\title{
Sleeping with the Enemy: Effective Representation under Dynamic Electoral Competition *
}

\author{
Anderson Frey \\ University of Rochester ${ }^{\dagger}$
}

\author{
Gabriel López-Moctezuma
}

California Institute of Technology
Sergio Montero

University of Rochester ${ }^{\dagger \S}$

December 14, 2020

\begin{abstract}
Electoral coalitions between ideologically incompatible parties - among other unconventional electoral strategies - may seem to threaten effective representation, signaling a breakdown of programmatic politics. However, this perspective overlooks parties' and voters' dynamic considerations. We propose and estimate a model of dynamic electoral competition in which a short-term ideology compromise, via an electoral coalition, offers opposition parties (and voters) the opportunity to remove an entrenched incumbent party from office, thus leveling the playing field in the future. This tradeoff provides a previously unrecognized rationale for coalition formation in elections. We take our model to data from Mexican municipal elections between 1995-2016 and show that coalitions between parties on opposite ends of the ideology spectrum have served as an instrument of democratic consolidation.
\end{abstract}

Keywords: coalitions, entrenched incumbency, dynamic electoral competition

Word Count: 9,924

${ }^{*}$ We are grateful to Adrián Lucardi and José Merino for sharing part of the data used in this paper. We also thank audiences at the Princeton-Warwick Political Economy Conference, IEA World Congress, MPSA, APSA, ITAM, Caltech, and Rochester for very helpful comments.

${ }^{\dagger}$ Department of Political Science, emails: anderson.frey@rochester.edu and smontero@rochester.edu.

${ }^{\ddagger}$ Division of the Humanities and Social Sciences, email: glmoctezuma@caltech.edu.

$\S$ 


\section{Introduction}

Growing discontent with democratic politics in recent years has revitalized research into the signs and origins of well-functioning democracy. Democratic stability, scholars have long argued, largely depends on voters finding acceptable alternatives at the polls (??). When political parties pursue unconventional electoral strategies (??) or compete for voters on nonprogrammatic grounds - e.g., through vote-buying or clientelism (?) — effective representation and the link between election outcomes, public policy, and government accountability may be threatened, fueling distrust of democratic institutions.

Electoral coalitions between ideologically incompatible parties constitute a stark example of such unconventional strategies. ${ }^{1}$ They pose a puzzle: if electoral competition is fundamentally based on contrasting coherent policy agendas and values, what do parties on opposite ends of the ideology spectrum have to gain from joining forces against more centrist rivals? Standard intuition from spatial voting models would predict little to no benefits from such alliances (?). Should they be taken, then, as evidence of a breakdown of programmatic politics?

Consider the case of Mexico. For almost its entire democratic history, the three main contenders in elections at all levels of government have been the Party of the Democratic Revolution (PRD), the Institutional Revolutionary Party (PRI), and the National Action Party (PAN). Voters and experts widely agree that, at the federal level, PRD and PAN are respectively located to the left and right of PRI on the ideology spectrum. Moreover, legislators' ideological preferences, as recovered from roll-call data, align perfectly with the ordinal ranking of the three parties. ${ }^{2}$ Yet, since the 1990s, PAN and PRD have nominated common candidates against PRI in several subnational elections.

Given Mexico's well-documented history of electoral fraud, vote-buying, and clientelism

\footnotetext{
${ }^{1}$ Throughout, we use the terms "electoral coalition" and "electoral alliance" interchangeably. Ideologically incompatible alliances have been regularly observed in, e.g., Latin America (?), Eastern Europe (?), India (?), Turkey (the longest coalition government since the 1960s involved the left-wing DSP and ultra-conservative MHP), and Greece (in 2015, the radical-left SYRIZA joined forces with the radical-right ANEL to oppose the center-right ND and center-left PASOK).

${ }^{2}$ See Section 3.
} 
(??), it is tempting to conclude that the PAN-PRD coalitions reveal a dilution of party brands at the local level and electoral competition based on the distribution of political favors rather than on well-defined policy preferences. However, we provide evidence against this conclusion. Using a regression-discontinuity design (RDD) on close elections, we demonstrate that Mexican mayors enact policies that are consistent with their party's ideology. Furthermore, we find that coalition and non-coalition mayors from the same party are indistinguishable with regard to policy choices, ruling out policy compromises as the cornerstone of the PAN-PRD alliance.

In this paper, we argue that accounting for parties' and voters' dynamic considerations is crucial to understanding the implications of seemingly unconventional electoral strategies. We propose and estimate a model of dynamic electoral competition that allows for strategic coordination between parties by way of common candidate nominations. In our model, holding office over time enables the incumbent party to (potentially) build an electoral advantage. Opposition parties and voters then face a stark dynamic tradeoff: a short-term ideology compromise, via an electoral coalition, offers the opportunity to remove the incumbent from office, deplete its electoral advantage, and thus level the playing field in the future. This tradeoff provides a rationale for coalition formation in elections previously unrecognized in the literature. ${ }^{3}$

We estimate our model using data from Mexican municipal elections between 1995-2016. Our estimation strategy directly tackles the selection problem that arises from parties' observed coalition choices being informed by features of the electoral environment that are unobserved by the researcher - e.g., candidates' valence or campaign efforts. We explicitly model and quantify the dynamic influence of such unobservables. ${ }^{4}$

Mexico provides an ideal setting in which to study the dynamics of electoral coalition formation for two reasons. First, at the subnational level, it has experienced decades of uninter-

\footnotetext{
${ }^{3}$ Existing studies of electoral (also called pre-electoral) coalitions have focused mostly on comparing their prevalence across electoral systems or on their role in shaping post-election government formation in parliamentary democracies, highlighting the ideological proximity of coalition partners (??).

${ }^{4}$ Our estimation strategy follows ?. For a recent example of structural estimation of a dynamic model of interstate conflict without persistent unobservables, see ?.
} 
rupted rule by PRI. ${ }^{5}$ Thus, entrenched incumbency — reinforced by widespread clientelism-is an especially salient dynamic consideration. Second, while the PAN-PRD coalitions might seem anomalous from a static perspective, our results show they are in fact consistent with a long-term coping strategy by parties facing a dynamically disadvantageous environment.

In line with our RDD evidence, we report structural estimates of Mexican parties' policy preferences at the municipal level, which coincide with their national profiles. That is, we find that, in any mayoral term, PAN and PRD would both prefer PRI to be in power instead of each other. It is therefore the dynamic tradeoff outlined above what rationalizes their electoral alliance. $^{6}$

More importantly, rather than evidencing weakened interest in programmatic politics at the local level, our results indicate that the PAN-PRD alliance has served as an instrument of democratic consolidation in Mexico. With our structural estimates in hand, we simulate election outcomes under a counterfactual scenario wherein we prevent PAN and PRD from ever joining forces, and we find that the hegemonic PRI would have won a share of municipal elections $21 \%$ higher than that observed in the data. Notably, the number of municipalities that have never experienced a transfer of power would have increased by $50 \%$. Thus, PANPRD coalitions have opened the door to effective democracy in Mexican local politics.

\subsection{Related Literature}

Our paper contributes to the broad literature on political competition in young and developing democracies. In these environments, parties often employ a portfolio of diverse electoral strategies that includes both non-policy appeals (?) and frequently-revised programmatic promises (?). Policy shifts are typically interpreted as resulting from a static tradeoff for parties between differentiation and appeal (?) — i.e., giving up programmatic differentiation

\footnotetext{
${ }^{5}$ While the victory of an opposition candidate in the 2000 presidential election arguably marked Mexico's official transition to democracy, by 2016, five states and 64 municipalities still had not experienced a transfer of power.

${ }^{6}$ We illustrate these incentives at work with a detailed case study in Section 5.4.
} 
might be beneficial whenever it credibly brings parties closer to a larger share of the electorate. ${ }^{7}$

Not surprisingly, unconventional coalitions in this context are often seen as a symptom of ideological shifts. For example, ? discusses how FREPASO in Argentina diluted its center-left brand after joining right-wing UCR in the "Alliance for Work, Justice and Education" against the Peronist party in 1997. Yet not all coalitions of the ends against the middle imply a decline in programmatic differentiation. In Brazil, e.g., a phenomenon similar to the Mexican case analyzed in this paper can be observed: although PT (left) and PSDB (right) have consistently remained at opposing ends of the ideology spectrum for the past two decades (?), they have entered into coalitions in several municipal elections. In Appendix F, we provide evidence that suggests the theoretical mechanism elucidated by our model may also be at work in these PT-PSDB alliances. We show that they are much more likely to emerge in municipalities where neither party has been successful in the past or where a large centrist party (MDB) has a strong presence.

Our theory provides a novel explanation for this puzzle by framing it as an intertemporal decision problem faced by parties and voters: short-term policy losses become acceptable whenever this leads to higher electoral competitiveness in the future and, thus, to a corresponding increase in the chances of getting their most preferred policies. In our framework, ideological positions are not adjusted but, rather, temporarily set aside, which creates the appearance of suboptimal short-term behavior. This intuition is present in ?'s (?) discussion of party competition in India: "Congress has been clearly defeated only when the opposition has been so consumed with intense popular hatred of Mrs. Gandhi or with intense elite lust for ministerial office that politicians and voters alike could put aside their ideological tastes and act as if they ordered their preferences with Congress at the bottom of the list." Thus, our model is geared toward political contexts where the ideological positions of parties are well established and informative of policy outcomes. ${ }^{8}$

Our paper also speaks to a burgeoning literature on the factors that influence countries'

\footnotetext{
${ }^{7}$ See ? for an overview of policy shifts.

${ }^{8}$ In other words, brand dilution is unlikely or slow-moving.
} 
transitions from one-party rule to more competitive democratic environments. One-party dominance often depends on the regime's ability to retain a monopoly over financial and institutional resources (?). Indeed, control of public resources was a pillar of PRI's longlasting electoral dominance in Mexico (?). In this context, we argue that the seemingly incongruent PAN-PRD coalitions have helped pave the way toward democratic consolidation: by cutting the entrenched PRI from the spoils of office, victorious PAN-PRD coalitions have increased the likelihood of future electoral success for both parties (??).

\section{Mexican Municipal Elections}

We focus our empirical analysis on municipal elections in Mexico between 1995-2016. The country is divided into 31 states plus the capital, Mexico City, which are further subdivided into more than 2,000 municipalities. Mayors are elected under first-past-the-post races, and they serve for three years without the possibility of re-election. ${ }^{9}$ Candidates are primarily funded by their political parties, which in turn rely mostly on public funding. Together, shortterm mandates, a constitutional ban on re-election, and strict limits on campaign finance and on independent candidacies have fostered an electoral system with very strong parties, where individual candidates have limited influence.

As noted, three parties have been the main contenders for public office at both the national and subnational levels. PRI, usually characterized as a broad center-left party, dominated Mexican politics for decades from its foundation in the 1920s to the late 1990s. PAN, viewed as center-right, has been the main opposition party since its creation in 1939. Lastly, PRD, considered a left-wing party, was founded in 1989 by PRI dissidents who united several socialist organizations under a common umbrella.

While re-election of individual politicians is forbidden in Mexico, parties have exploited their tenure of public offices to build an electoral advantage over their opposition. Partiesparticularly the hegemonic PRI - have followed a strategy of selective reward and punishment,

\footnotetext{
${ }^{9} \mathrm{~A}$ constitutional reform in 2014 introduced the possibility of re-election starting in 2018.
} 
using public resources to nurture loyal voters through clientelistic and patronage networks, while similarly penalizing the opposition (?).

Figure 1 shows the evolution of parties' municipal election victories since the $1990 \mathrm{~s}^{10}$ Two features stand out. On one hand, the plot illustrates the gradual democratization of Mexican subnational politics taking place in this period, with a steadily increasing share of municipalities experiencing effective electoral competition and transitions of power. On the other, it shows that, by 2016, PRI still controls close to $40 \%$ of municipalities.

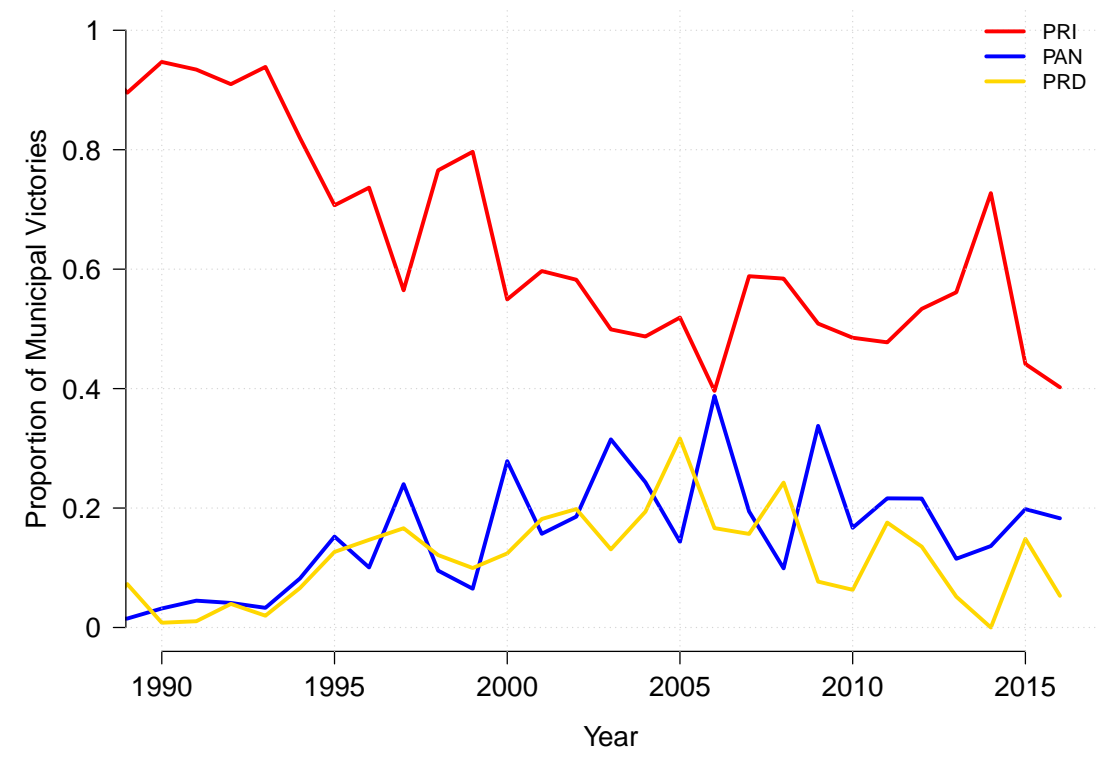

Figure 1: Evolution of Parties' Municipal Election Victories

Concurrently in this period - starting in 1988-Mexican parties have been allowed to join forces in elections through common candidate nominations. Coalition agreements are negotiated by party leaders prior to each election, and they must be publicly registered before the corresponding electoral authority - federal or state. For local elections, these agreements are binding and specify, for each municipality: (i) whether the coalition partners will nominate a joint candidate or independent candidates, and (ii) in the case of a joint nomination, from which party's ranks will the coalition candidate be drawn. Importantly, coalition victors retain their original party affiliation once in power and are not bound to any particular policy

\footnotetext{
${ }^{10}$ We describe our data and sources in Section 4.3.
} 
platform.

Figure 2 plots the evolution of the proportion of municipal elections with PAN-PRD coalition candidates. As shown, PAN and PRD began experimenting with joint candidate nominations in a few municipalities between 1999-2009. Since 2010, however, the two parties have systematically deployed joint nominations in about a fifth of the country. ${ }^{11}$ Figure B1 in Appendix B illustrates the considerable variation across municipalities-both within and across states - and over time in the extent and configuration of the PAN-PRD alliance, which underscores its strategic nature.

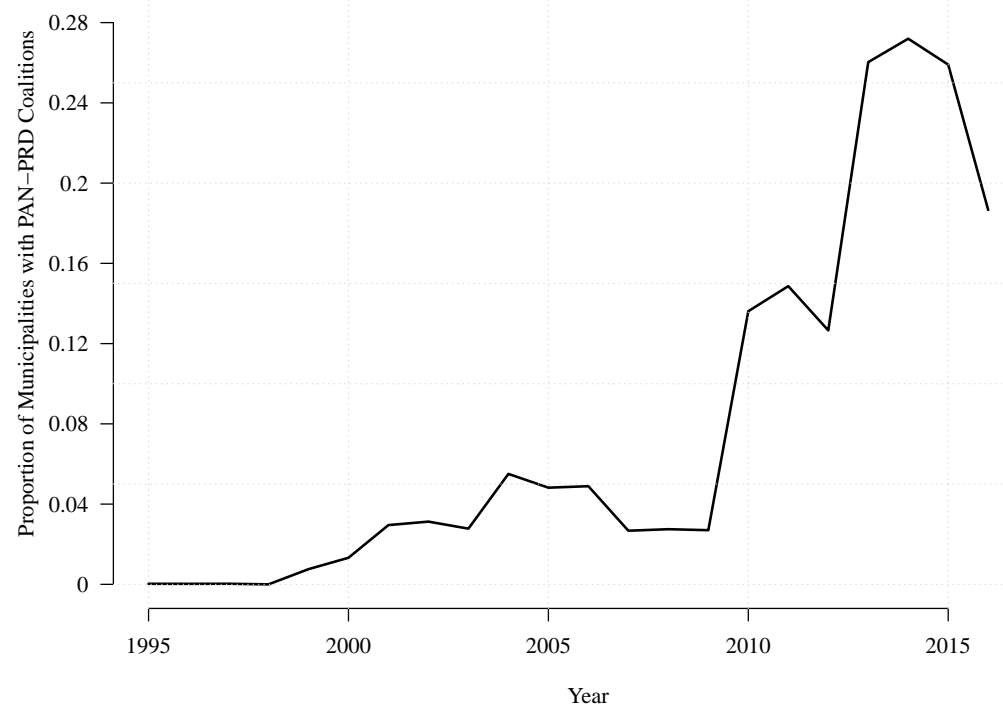

Figure 2: PAN-PRD Coalitions over Time

Notes. This figure plots a two-cycle moving average of the proportion of municipal elections featuring PANPRD coalition candidates between 1995-2016.

\section{Programmatic Politics in Mexico}

A potential explanation for the emergence of electoral coalitions between ideologically incompatible parties is that policy preferences and party labels are in fact irrelevant for electoral competition in developing democracies such as Mexico. When parties prioritize the distribution of discretionary funds and personal favors over contrasting coherent policies and values,

\footnotetext{
${ }^{11}$ The 2009 midterm elections witnessed a remarkable comeback by PRI since it lost the presidency.
} 
there are clear returns to scale from coalition formation, with limited ideological costs. However, we begin our analysis by showing that this narrow view is hard to reconcile with the Mexican experience. We provide evidence that, despite rampant vote-buying and clientelism, Mexican parties retain clear and consistent ideological positions, both at the national and subnational levels.

Pertaining to parties' national platforms, Figure A1 in Appendix A shows that voters and experts widely agree that PRD, PRI, and PAN can be placed in that order on a left-right ideology spectrum. Furthermore, using roll-call data, we demonstrate that federal legislators' policy preferences are consistent with their party's perceived ideology. Specifically, as shown in the bottom-right panel of Figure A1, estimates of legislators' ideal points locate all PRD legislators to the left of PRI's, who in turn are all to the left of PAN's.

\subsection{Municipal Policy Choices}

Beyond national politics and party labels, little is known about the ideological congruence between Mexican local politicians and parties' national platforms. We fill this gap by providing novel evidence that elected mayors' policy choices indeed align with their party's ideology. We estimate a regression-discontinuity design (RDD) that exploits narrow margins of victory in municipal elections to generate causal estimates of the effect of party labels on policy choices (?). Our outcome of interest is social spending as a percentage of the three-year municipal budget, for which we have clear expectations of parties' preferences according to ideology. ${ }^{12}$ We use data on close elections between a PRI candidate and a - coalition or independentPAN or PRD candidate. Our sample covers 1,898 municipalities between 1999-2015.

Figure 3 presents our results. The plot includes all elections with a margin of victory within 20 percentage points, and solid lines correspond to local quadratic trends for the social spending of each winning party. ${ }^{13}$ Municipalities with close PRD victories devote, on average,

\footnotetext{
${ }^{12}$ Municipal public finance data can be obtained from the National Statistics and Geography Institute (INEGI).

${ }^{13}$ Table B1 in Appendix B shows robust results for a narrower bandwidth and a local linear fit. The total number of elections in Figure 3 is 6,167. PAN-PRD coalitions are present in 513 of these observations.
} 
about 4 percentage points more of their budget to social spending than municipalities with close PRI wins - a $13 \%$ increase. In turn, municipalities with close PAN victories devote around 2 percentage points less to social spending than municipalities with close PRI wins - a $7 \%$ decrease. These effects are consistent with the national policy platforms of the three major parties - see Figure A1 in Appendix A.

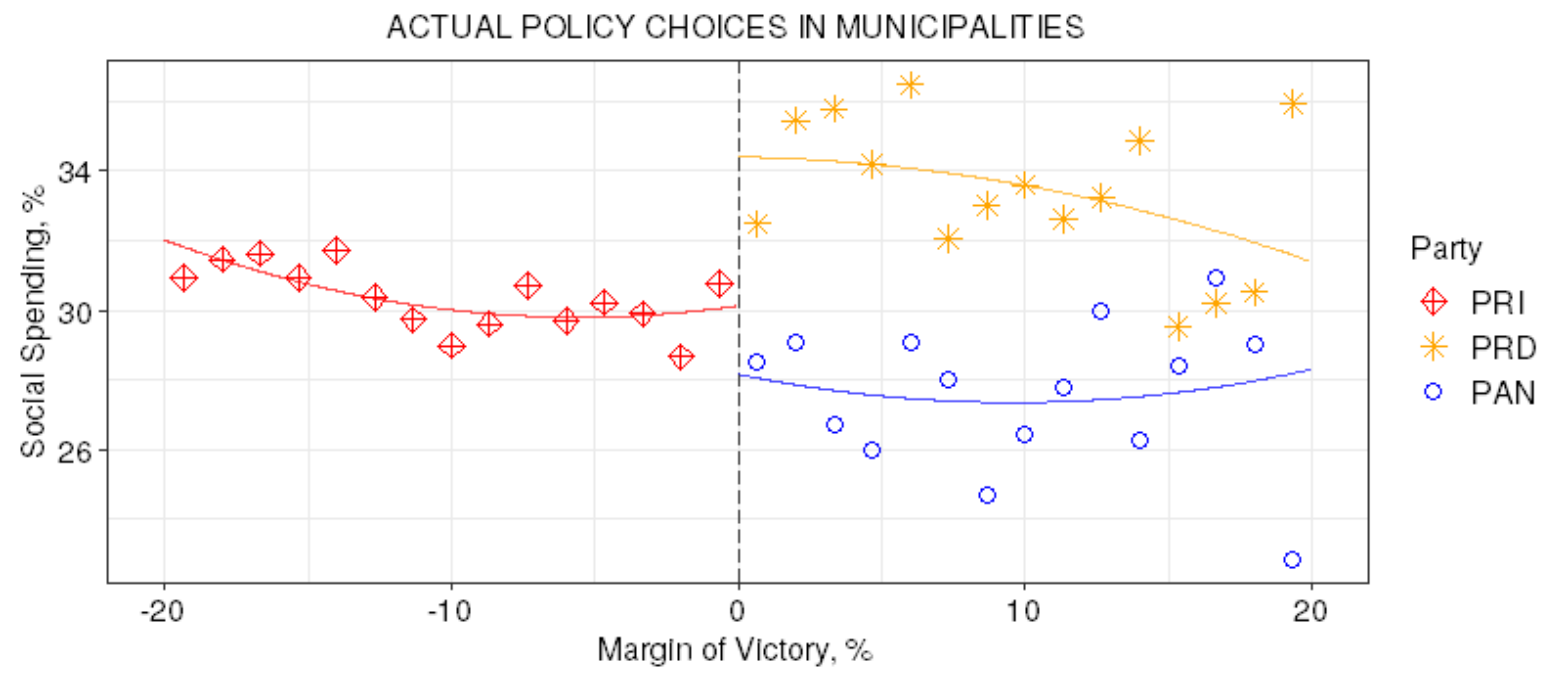

Figure 3: Municipal Social Spending by Party

Notes. This figure plots social spending as a percentage of the three-year municipal budget against PAN or PRD mayoral margin of victory for the period 1999-2015, where a negative margin indicates a PRI win. Each point represents the average value of the outcome in vote-spread bins of one percentage point. Solid lines depict predicted values, with separate quadratic trends for each party.

Moreover, we find no evidence of policy compromise concerning coalition mayors. Table B1 in Appendix B shows that the policy choices of both PAN and PRD coalition mayors are statistically indistinguishable from those of corresponding non-coalition mayors. ${ }^{14}$

These results strongly suggest that, by nominating common candidates, PAN and PRD risk sacrificing, at least in the short run, their ideal policy for one that is more extreme than what would be implemented by the hegemonic, but centrist, PRI. We take this as our starting point for the model of electoral competition that we develop in the following section. To understand the emergence of PAN-PRD coalitions, we argue that parties' and voters'

\footnotetext{
${ }^{14}$ In fact, while statistically insignificant, the coefficient estimates suggest that the gap between PAN and PRD's policy choices may be even greater for coalition mayors.
} 
dynamic considerations must take center stage.

\section{A Model of Dynamic Electoral Competition}

\subsection{Preliminary Evidence}

Before describing our model, we present some descriptive evidence that sheds light on the relevant predictors of coalition formation in the data. While these results do not account for parties' strategic motives when deciding whether to nominate common candidates, they reveal systematic empirical patterns that underlie key modeling choices in Section 4.2.

The left-hand panel of Figure 4 plots estimates from a Bayesian logistic regression of a binary indicator of PAN-PRD coalition formation on a measure of PRI entrenchment in power, controlling for municipality and electoral-cycle random effects. As discussed in Section 2, there are reasons to expect that Mexican parties - especially the hegemonic PRI - may exploit their time in power to progressively build an electoral advantage over their rivals. In line with this perspective, we construct a measure of entrenched incumbency that goes beyond simply considering whether the party is in power at the time of the election. Rather, we wish to account for the entire recent history of incumbency by each party. Figure 2 makes clear that the PAN-PRD coalitions were deployed in full force beginning in 2010, which we take as the starting point for our analysis. We then construct a measure of entrenched incumbency using the share of the past five electoral cycles won by each party. ${ }^{15}$

As shown in Figure 4, PAN-PRD coalitions are more likely in PRI municipal strongholds than elsewhere. We find that, while the probability of a PAN-PRD coalition is only $20 \%$ in a municipality where PRI has not governed for the past five electoral cycles, this probability almost doubles to $40 \%$ in a municipality with five cycles of uninterrupted PRI rule. ${ }^{16}$

\footnotetext{
${ }^{15}$ Our results are robust to alternative windows of incumbency and to expanding the sample to include the period 1999-2009, during which PAN and PRD proposed joint candidates in only $1.5 \%$ of municipal elections-see Appendix E.

${ }^{16}$ In Appendix C, we further explore the dynamics of PAN-PRD coalition formation - in particular, the impact of past coalition choices and their electoral success on the likelihood and expected duration of future PAN-PRD coalitions.
} 

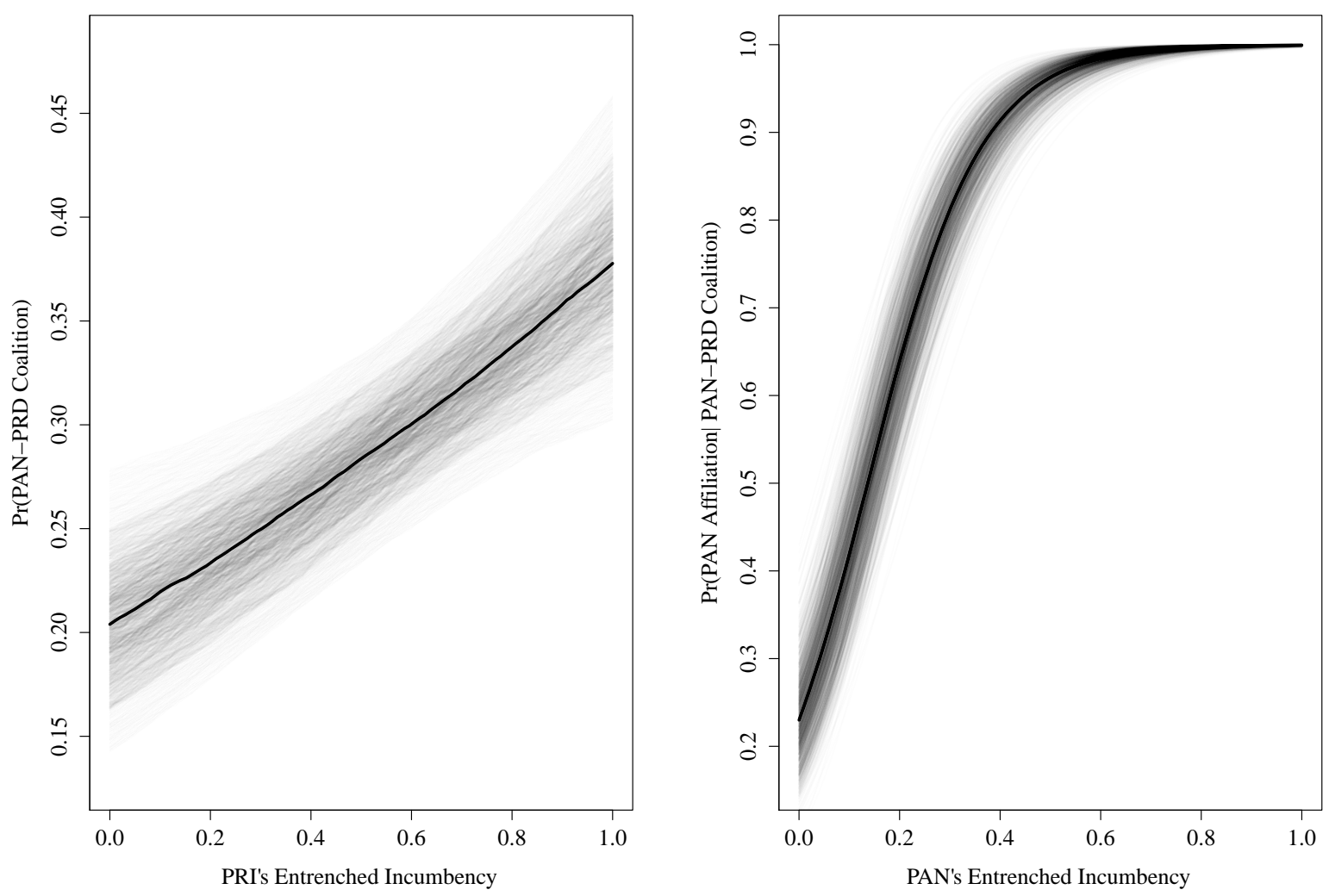

Figure 4: PAN-PRD Coalition Choices and Entrenched Incumbency

Notes. The left-hand plot shows the predicted probability of PAN-PRD coalition formation as a function of PRI's entrenchment. The right-hand plot shows the predicted conditional probability of a PAN candidate headlining the PAN-PRD coalition as a function of PAN's entrenchment. Estimates are from Bayesian logistic regressions, and shaded areas cover $95 \%$ confidence intervals. As we manipulate a party's incumbency history, we set the ratio of other parties' incumbency histories equal to the median in the data.

To examine the nature of PAN-PRD coalitions - i.e., which party headlines the coalitionthe right-hand panel of Figure 4 plots the predicted conditional probability that PAN and PRD jointly nominate a PAN candidate as a function of PAN entrenched incumbency. These estimates are also from a Bayesian logistic regression with municipality and electoral-cycle random effects. Perhaps unsurprisingly, we find that the party affiliation of PAN-PRD coalition candidates is largely determined by the relative strength of the coalition partners. In municipalities where PAN has not governed for the past five electoral cycles, the probability that a PAN candidate leads the PAN-PRD coalition is $25 \%$. However, PAN almost surely leads the coalition in its municipal strongholds. 
Lastly, we look at the electoral success of PAN-PRD coalition candidates. First, we fit a Bayesian multinomial logit model of parties' electability given our measures of entrenched incumbency, controlling for municipality and electoral-cycle random effects. The left-hand panel of Figure 5 shows the resulting predicted probabilities of victory for PAN, PRI, PRD, and other parties as a function of PRI entrenchment. In accordance with the discussion in Section 2, as PRI's entrenchment increases, its probability of victory rises markedly, ranging from $28 \%$ to almost $60 \%$, which is considerable given that these are multi-candidate races.
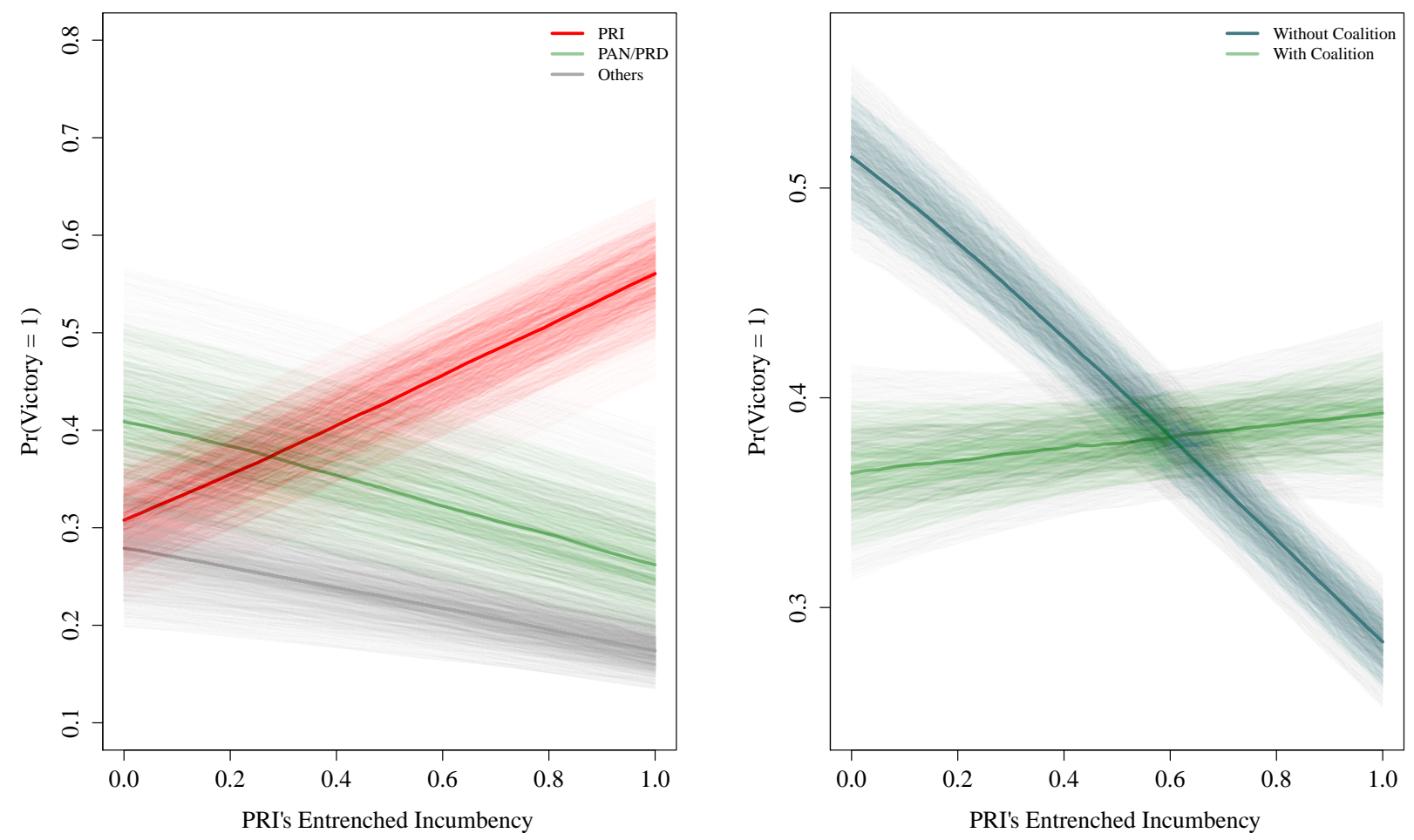

Figure 5: Probability of Victory in Municipal Elections

Notes. The left-hand panel shows the predicted probability of victory by each party (PRI, PAN, PRD, others) as a function of PRI's entrenchment. The right-hand panel focuses on the probability of victory by a PAN or PRD candidate conditional on the parties either forming or not an electoral coalition. Estimates are from Bayesian multinomial logit regressions, and shaded areas cover $95 \%$ confidence intervals. As we manipulate PRI's incumbency history, we set the ratio of other parties' incumbency histories equal to the median in the data.

Focusing on the electability of PAN and PRD candidates, the right-hand panel of Figure 5 plots the predicted probability of victory of coalition versus independent candidates as a function of PRI entrenchment. While independent candidates fare worse in PRI strongholds, 
coalition candidates' prospects are relatively better given high levels of PRI entrenchment. Though we cannot disentangle the causes with these reduced-form regressions, the evidence is consistent with the dynamic tradeoff at the heart of our argument. In line with standard spatial-voting intuition, PAN and PRD pay a considerable cost at the polls from forming an ideologically incompatible coalition in races against the hegemonic PRI that are relatively competitive. However, when PRI entrenchment is high, voters are seemingly willing to temporarily put their ideological tastes aside to support PAN-PRD coalition candidates.

Next, we formalize this intuition and describe our estimation strategy, which carefully accounts for potential unobserved confounders in the above descriptive evidence.

\subsection{Model}

We consider the choice by political parties engaged in repeated electoral competition to coordinate their efforts via coalition agreements. With an eye toward our empirical application, and for ease of exposition, we analyze this choice in a stylized environment with only four parties-PRI, PAN, PRD, and OTHER - where the prospect of coalition formation is entertained solely by PAN and PRD. ${ }^{17}$

In each municipality $m \in\{1, \ldots, M\}$ and electoral cycle $t \in\{1,2, \ldots\}$, parties compete under a first-past-the-post system to fill a single executive position. Prior to the election, the leadership of PAN and PRD jointly decide whether to participate independently - nominating distinct candidates - or to form an electoral alliance - nominating a common candidate. If they decide to join forces, the coalition partners must also agree on the party affiliation of the coalition candidate. That is, PAN and PRD repeatedly face the choice to nominate independent candidates (denoted $j=0$ ), a PRD coalition candidate $(j=-1$ ), or a PAN coalition candidate $(j=1)$. Although selecting $j=0$ implies that PAN and PRD do not form

\footnotetext{
${ }^{17}$ It is straightforward to allow for more complex coalition arrangements. However, coalitions involving PRI and either PAN or PRD are not supported by the data, rendering them superfluous given the scope of this paper: PRI's observed overwhelming strength eliminates any incentive for such alliances. Furthermore, coalitions headlined by other parties are extremely rare and dropped from our sample (our results are robust to this omission).
} 
a coalition in that contest, for convenience we refer to the two potential coalition partners simply as "the coalition" given that they can exercise the option at any time. We denote by $\mathcal{J}=\{-1,0,1\}$ the set of alternatives available to the coalition.

The remaining parties, PRI and OTHER, participate independently in each election. Thus, given the coalition's choice $j \in \mathcal{J}$, the menu of competing candidates, denoted $C_{j}$, always features a PRI candidate and an OTHER candidate. Additionally, menu $C_{j}$ may include either a PRD coalition candidate if $j=-1$, a PAN coalition candidate if $j=1$, or both PRD and PAN candidates if $j=0$. We denote by $\mathcal{C}=\left\{C_{j}\right\}_{j \in \mathcal{J}}$ the set of potential menus.

Parties are infinitely lived and maintain fixed policy positions over time that are commonly known by voters and all other parties. In other words, party labels are synonymous with ideology. We specify the per-cycle payoff party $p \in\{1, \ldots, P\}$ derives from the outcome of an election as follows. Without loss of generality, we normalize the payoff of winning to zero. Whenever, on the other hand, party $p^{\prime} \neq p$ wins the election, the payoff $p$ obtains is given by the coefficient $\theta_{p p^{\prime}}$. We make no attempt to separately quantify parties' office and policy motivations. Nevertheless, this simple payoff structure suffices to evaluate the relevance of party labels and, thus, ideology. If party labels are meaningless, one should expect the estimated value of $\theta_{p p^{\prime}}$ to be constant across all $p^{\prime} \neq p$, simply measuring the opportunity cost to $p$ of foregone rents from office. However, if parties indeed care about the policies enacted by their ideological rivals, $\theta_{p p^{\prime}}$ should additionally reflect (dis)utility from such policies, which would depend on the identity of the party in power.

Given these payoffs, the coalition partners base their decision of whether or not to nominate a joint candidate on their assessment of their electoral prospects with and without an electoral alliance. To forecast their electoral performance, parties rely on three pieces of information. First, they observe the recent hold on power by each party in the race. ${ }^{18}$ As discussed in Section 4.1 , this is given by the history of victories by each party $p$ in the past $N$ electoral

\footnotetext{
${ }^{18}$ While other scholars have disentangled pure incumbency effects from other relevant factors including name recognition, accountability, clientelistic networks, or campaign resources (?), we make no such attempt. We allow incumbency status to bundle all potential advantages - in particular, clientelism - parties may exploit from their time in power.
} 
cycles: $I_{m t}=\left(I_{m t}^{p}\right)_{p=1}^{P}$, where $I_{m t}^{p}=\left(w_{m, t-1}^{p}, \ldots, w_{m, t-N}^{p}\right)$ and $w_{m \tau}^{p}$ is a binary indicator of whether party $p$ won $\left(w_{m \tau}^{p}=1\right)$ or lost $\left(w_{m \tau}^{p}=0\right)$ the election in municipality $m$ at time $\tau$.

Parties also pay attention to the quality or valence of potential candidates when deciding whether to form a coalition. With a slight abuse of notation, we let $\xi_{m t}=\left(\xi_{m t}^{p}\right)_{p \in \cup_{j \in \mathcal{J}} C_{j}}$ collect the valence of all potential candidates - treating independent and coalition candidates from the same party as distinct - where $\xi_{m t}^{p}=-1$ represents a "bad" candidate from party $p, \xi_{m t}^{p}=0$ represents an "average" candidate, and $\xi_{m t}^{p}=1$ represents a "good" candidate. This dimension - unobservable to the researcher - corresponds to non-policy factors voters may value that are not captured by $I_{m t}$. Importantly, $\xi_{m t}$ may reflect not only candidatespecific attributes, such as competence or charisma, but also the intensity of campaign efforts by parties. Since pooling campaign resources in support of a common candidate may be advantageous to coalition partners, our model explicitly accounts for the potential influence of these unobservables on observed coalition choices. In particular, a candidate from the same party may have higher valence as a coalition candidate than as independent due to the added support and campaign resources provided by the coalition partner.

Lastly, parties take into consideration the socioeconomic characteristics of the electorate at the time of election, which are described by a $K \times 1$ vector of (exogenous) covariates $x_{m t}$ that may differentially affect parties' electoral prospects. Additionally, $x_{m t}$ includes characteristics of the electoral cycle itself, such as whether there are concurrent elections at the state or federal level, which allows us to control for cyclical features of the electoral environment.

Prior to ballots being cast, the state of the election in municipality $m$ at time $t$ is described by $z_{m t}=\left(I_{m t}, \xi_{m t}\right)$, which collects parties' incumbency histories and candidates' valence. ${ }^{19}$ Given the coalition's choice $j \in \mathcal{J}$, the probability that party $p \in C_{j}$ wins the election $\left(w_{m t}^{p}=1\right)$ takes the flexible form

$$
f_{j m t}^{p}\left(z_{m t} ; \beta\right)=\frac{\exp \left(x_{m t}^{\prime} \beta_{x}^{p}+\iota\left(I_{m t}^{p}, \alpha\right) \beta_{I}+\xi_{m t}^{p}\right)}{\sum_{p^{\prime} \in C_{j}} \exp \left(x_{m t}^{\prime} \beta_{x}^{p^{\prime}}+\iota\left(I_{m t}^{p^{\prime}}, \alpha\right) \beta_{I}+\xi_{m t}^{p^{\prime}}\right)},
$$

\footnotetext{
${ }^{19}$ We exclude the exogenous $x_{m t}$ from $z_{m t}$ and subsume it in the description of the electoral cycle $(m, t)$.
} 
where $\alpha \in[0,1]$ is a discount factor, $\iota\left(I_{m t}^{p}, \alpha\right)=\sum_{n=1}^{N} \alpha^{n-1} w_{m, t-n}^{p}$ measures party $p$ 's net accumulated incumbency at time $t$, and $\beta=\left(\left(\beta_{x}^{p}\right)_{p \in\{1, \ldots, P\}}, \beta_{I}, \alpha\right)$ is a vector of parameters to be estimated. ${ }^{20}$

Equation (1) parsimoniously captures the key determinants of election outcomes. First, $\iota\left(I_{m t}^{p}, \alpha\right)$ relaxes our entrenched incumbency measure from Section 4.1 by introducing a discount factor $\alpha .{ }^{21}$ This parameter determines how quickly the electoral importance of incumbency depreciates over time. If parties indeed exploit their time in power to build long-lasting political capital or ties to vulnerable segments of the electorate, then $\alpha$ should be close to one. However, if incumbency effects arise simply from holding office at the time of the election, $\alpha$ should be close to zero. Second, parties' probability of winning depends on the composition, $x_{m t}$, and partisan preferences, $\beta_{x}^{p}$, of the electorate. Finally, any residual factors affecting parties' electability are captured through unobserved valence, $\xi_{m t}^{p}$.

We model candidates' valence as independently distributed across municipalities and over time, drawn from a distribution $\pi\left(\xi_{m t} \mid x_{m t}\right)$ - to be estimated - that may condition on observable characteristics in $x_{m t}$. We do not impose any restrictions on the joint distribution of valence across parties or menus.

Given Equation (1) and parties' policy payoffs described above, party $p$ 's expected flow payoff in municipality $m$ at time $t$ under coalition choice $j \in \mathcal{J}$ is given by

$$
u_{j m t}^{p}\left(z_{m t} ; \theta, \beta\right)=\sum_{p^{\prime} \in C_{j}} \theta_{p p^{\prime}} f_{j m t}^{p^{\prime}}\left(z_{m t} ; \beta\right),
$$

where $\theta_{p p}=0$, as discussed, and the vector $\theta$ collects all parties' policy payoffs - to be estimated. The coalition's joint per-period surplus is then a weighted average of the partners'

\footnotetext{
${ }^{20}$ To capture pooled support of a joint candidate by the two coalition partners, we include in $\iota\left(I_{m t}^{p}, \alpha\right)$ for a coalition candidate the incumbency status of either partner-i.e., $w_{m, \tau}^{p}=1$ if either PAN or PRD won the election at time $\tau$. Our main results are virtually unchanged if we instead let $\iota\left(I_{m t}^{p}, \alpha\right)$ be party specific.

${ }^{21}$ Note that the entrenchment measure from Section 4.1 equals $\iota\left(I_{m t}^{p}, 1\right) / 5$.
} 
individual flow payoffs:

$$
U_{j m t}\left(z_{m t} ; \varphi\right)=\lambda_{s(m)} u_{j m t}^{\mathrm{PAN}}\left(z_{m t} ; \theta, \beta\right)+\left[1-\lambda_{s(m)}\right] u_{j m t}^{\mathrm{PRD}}\left(z_{m t} ; \theta, \beta\right)
$$

where $s(m)$ denotes the state to which municipality $m$ belongs. As noted in Section 2, coalition agreements are drafted and registered at the state level. Furthermore, in line with the descriptive evidence in Section 4.1, and letting $M_{s}$ denote the set of municipalities in state $s$,

$$
\lambda_{s}=\frac{\exp \left(\beta_{\lambda} \sum_{m \in M_{s}} \frac{\iota\left(I_{m 1}^{\mathrm{PAN}}, 1\right)-\iota\left(I_{m 1}^{\mathrm{PRD}}, 1\right)}{\left|M_{s}\right|}\right)}{1+\exp \left(\beta_{\lambda} \sum_{m \in M_{s}} \frac{\iota\left(I_{m 1}^{\mathrm{PAN}}, 1\right)-\iota\left(I_{m 1}^{\mathrm{PRD}}, 1\right)}{\left|M_{s}\right|}\right)}
$$

parameterizes PAN's relative bargaining power in state $s$ as a function of its initial average advantage in entrenched incumbency over PRD, where $\beta_{\lambda}$ is a parameter to be estimated. ${ }^{22}$ The vector $\varphi=\left(\theta, \beta, \beta_{\lambda}, \pi\right)$ collects all the parameters of the model.

Coalition partners take into consideration that their choices affect not only their current payoffs but also their future electoral prospects through changes in incumbency histories. Given a discount factor $\delta \in(0,1)$, the goal of the coalition is to sequentially choose coalition arrangements so as to maximize their expected discounted total joint surplus. In each contest, we allow the coalition to experience an idiosyncratic shock $\epsilon_{j m t}$ to the joint surplus from choosing $j \in \mathcal{J}$. These shocks can be interpreted as transient bargaining costs from committing to arrangement $j$, and they are observed by the coalition partners but not the researcher. As is standard, we assume that $\epsilon_{m t}=\left(\epsilon_{j m t}\right)_{j \in \mathcal{J}}$ are independently drawn from the mean-zero Type-I Extreme Value (TIEV) distribution.

Letting $d_{j m t}=1$ if the coalition chooses arrangement $j$ in municipality $m$ at time $t$, and $d_{j m t}=0$ otherwise, the coalition seeks to maximize

$$
\sum_{m=1}^{M} \sum_{t=1}^{\infty} \delta^{t-1} \sum_{j \in \mathcal{J}} d_{j m t} E_{t}\left[U_{j m t}\left(z_{m t} ; \varphi\right)+\epsilon_{j m t}\right] .
$$

\footnotetext{
${ }^{22}$ Our results are robust to allowing bargaining power be municipality-specific.
} 
Note that, since electoral rules allow the coalition partners to choose any configuration for their alliance across municipalities, objective (2) is separable across $m \in\{1, \ldots, M\} .{ }^{23}$

Given $\left(z_{m t}, \epsilon_{m t}\right)$, let $V_{m t}\left(z_{m t}, \epsilon_{m t} ; \varphi\right)$ denote the value function of the coalition's dynamic decision problem in municipality $m$ at time $t$. This value function gives the maximum expected discounted joint surplus the coalition partners can attain from time $t$ onward. Standard results from the theory of dynamic programming imply that this value function can be written as

$$
V_{m t}\left(z_{m t}, \epsilon_{m t} ; \varphi\right)=\max _{j \in \mathcal{J}}\left\{v_{j m t}\left(z_{m t} ; \varphi\right)+\epsilon_{j m t}\right\}
$$

where the conditional value functions $v_{j m t}\left(z_{m t} ; \varphi\right)$ satisfy

$$
v_{j m t}\left(z_{m t} ; \varphi\right)=U_{j m t}\left(z_{m t} ; \varphi\right)+\delta E_{t}\left[\max _{j^{\prime} \in \mathcal{J}}\left\{v_{j^{\prime}, m, t+1}\left(z_{m, t+1} ; \varphi\right)+\epsilon_{j^{\prime}, m, t+1}\right\} \mid d_{j m t}=1, z_{m t}\right] .
$$

The expectation in Equation (4) is taken conditional on the state of the election and on the coalition choosing alternative $j$ at time $t$.

Together, Equations (3) and (4) make clear the essence of the coalition's decision problem and the key dynamic tradeoff they face. While (3) resembles a static discrete-choice problem, in that optimal behavior at time $t$ compels the coalition to choose a best alternative $j$ given bargaining shocks $\epsilon_{m t}$, notice that $v_{j m t}\left(z_{m t} ; \varphi\right)$ is composed of two terms. The first, $U_{j m t}\left(z_{m t} ; \varphi\right)$, is the coalition's immediate surplus from choosing $j$, which depends on the partners' expected policy payoffs from the outcome of the election at time $t$. From this short-term perspective, if PAN and PRD's preferences align with the results in Section 3, neither party has an incentive to stand down in support of its partner's candidate. Doing so means forgoing their favorite outcome — winning the election — while raising the probability of their least preferred outcome - their partner winning the election. However, the second term on the right-hand side of (4) captures the potential benefit of joining forces: choosing $j \neq 0$

\footnotetext{
${ }^{23}$ To avoid overcomplicating the analysis, rather than explicitly modeling bargaining between the coalition partners in this dynamic environment, we assume that the parties are able to coordinate on some agreement on their Pareto frontier, which we pinpoint by estimating $\lambda_{s(m)}$. This weight can be viewed as establishing the "terms of trade" in state $s$.
} 
at time $t$, and thus influencing the outcome of the election, may lead to a more favorable state $z_{m, t+1}$ in the next electoral cycle. We show in Section 5 that this is indeed the rationale behind PAN-PRD coalitions.

\subsection{Empirical Strategy}

Data. As noted in Section 4.1, for each municipality $m$ in our sample we take the first electoral cycle since 2010 as $t=1$, and we use the previous $N=5$ cycles (going back to $1995)$ to build $I_{m 1}$. For $M=1790$ municipalities, we observe up to $T_{m} \leq 3$ electoral cycles of characteristics of each municipality, $x_{m t}$, and parties' recent incumbency histories, $I_{m t}$. Election results are published by state electoral authorities. Coalition choices are available from local coalition agreements obtained via transparency requests to the electoral authorities.

Socioeconomic information about the electorate in $x_{m t}$ is obtained from INEGI and INAFED, a decentralized federal agency tasked with monitoring municipal development. ${ }^{24}$ We also control in $x_{m t}$ for concurrent gubernatorial, congressional, and presidential elections. Lastly, while we do not have enough observations to include municipality fixed effects in $x_{m t}$, we add dummies for the five national electoral regions (circunscripciones) as designated by the federal electoral authority, INE. Our main results are robust to alternative specifications. ${ }^{25}$

Likelihood. While we relegate a detailed derivation of the likelihood of the data to Appendix $\mathrm{D}$, we briefly describe here the intuition. At the start of electoral cycle $t$, the coalition partners observe the state of the election, $z_{m t}$. Given $\varphi$ (and our distributional assumption regarding $\left.\epsilon_{m t}\right)$, optimal dynamic behavior, as described by Equations (3) and (4), compels the parties to select - from the perspective of the researcher, who doesn't observe $\epsilon_{m t}$-coalition arrangement

\footnotetext{
${ }^{24}$ Table B2 in Appendix B provides summary statistics.

${ }^{25}$ In Appendix E, we explore the robustness of our findings to key modeling and sample choices. In particular, we report results using an expanded sample covering 1999-2016 as well as specifications setting $N=4$, restricting unobserved valence to $\xi^{p} \in\{0,1\}$, controlling for the party affiliation of the incumbent state governor, and exploring whether there are direct electoral benefits from supporting a coalition partner's candidate. Our main conclusions are virtually unchanged. Notably, we find no direct benefits from being a "junior" coalition partner.
} 
$j \in \mathcal{J}$ with probability

$$
l_{j m t}\left(z_{m t} ; \varphi\right)=\frac{\exp \left[v_{j m t}\left(z_{m t} ; \varphi\right)\right]}{\sum_{j^{\prime} \in \mathcal{J}} \exp \left[v_{j^{\prime} m t}\left(z_{m t} ; \varphi\right)\right]}
$$

Conditional on this choice, the outcome of the election in period $t$ is determined by the

probabilities of victory, $f_{j m t}^{p}\left(z_{m t} ; \beta\right)$. Parties' incumbency histories then evolve to $I_{m, t+1}^{p}$, a new set of candidates, $\xi_{m, t+1}$, is drawn from $\pi$, and thus the state of the election transitions to $z_{m, t+1}=\left(I_{m, t+1}, \xi_{m, t+1}\right)$.

A crucial challenge in estimation, however, is that candidates' valence, $\xi_{m t}$, in $z_{m t}$ is unobserved by the researcher and, thus, must be integrated out to obtain the likelihood of the observed data. We follow the two-stage estimation procedure proposed by ? to recover the parameters of our model. In a first stage, we use a semiparametric estimator of $l_{j m t}\left(z_{m t} ; \varphi\right)$ and the Expectation-Maximization (EM) algorithm to produce estimates of $\beta$ and $\pi$. In a second stage, we exploit Equation (5) to construct a Generalized Method of Moments (GMM) estimator of the remaining parameters, $\theta$ and $\beta_{\lambda}$. See Appendix D for details.

\section{Results}

We present four sets of results that summarize the main implications of our structural estimation exercise. First, we report estimates of parties' probabilities of victory. In particular, we quantify the electoral importance of incumbency history and unobserved valence, and we illustrate the key dynamic tradeoff faced by coalition partners. Second, we present estimates of parties' payoffs. Third, we perform a counterfactual experiment that explores the role of PAN-PRD coalitions as an instrument of democratic consolidation in Mexico. We conclude by analyzing in detail PAN-PRD coalition choices and their implications in a particular state as a case study. ${ }^{26}$

\footnotetext{
${ }^{26}$ See Appendix B for model fit.
} 


\subsection{Electoral Performance}

Parties' electoral performance is governed in our model by Equation (1), which is parameterized by $\beta=\left(\left(\beta_{x}^{p}\right)_{p \in\{1, \ldots, P\}}, \beta_{I}, \alpha\right)$. Table B3 in Appendix B reports our estimates of $\left(\beta_{x}^{p}\right)_{p \in\{1, \ldots, P\}}$, the coefficients that describe how election outcomes are shaped by observable (exogenous) characteristics of the electoral environment. Overall, our results are consistent with well-known patterns of partisanship in Mexico. For instance, municipalities with older electorates tend to favor the three established national parties - PAN, PRI, PRD - over others, and municipalities with a higher share of female voters tend to favor the left-wing PRD, which was the first to decriminalize abortion in Mexico City. However, in contrast to previous studies that document strong support for PRI in rural communities, we find that the link disappears once one controls for entrenched incumbency. This suggests, as discussed in Section 2, that PRI's strength in rural areas is due not to latent partisanship but to historical entrenchment that the party has successfully exploited to build ties with vulnerable voters $(?)$.

The remaining coefficients, $\left(\beta_{I}, \alpha\right)$, measure the electoral importance of holding on to power and its persistence. We estimate $\hat{\beta}_{I}=0.235$ and $\hat{\alpha}=0.968$, with standard errors 0.027 and 0.045 , respectively. In line with the discussion in Section 2, these estimates imply that holding office brings about substantial electoral benefits that depreciate very slowly over time, at a rate of approximately $3 \%$ per electoral cycle. Thus, dynamic considerations are an especially salient feature of electoral competition in this context.

To better illustrate the substantive implications of our estimates, we plot in the top-left panel of Figure 6 each party's probability of victory as a function of PRI's time in power. Specifically, we set observable covariates equal to their sample means and unobserved valence to zero - i.e., an "average" candidate - for all parties, using our coefficient estimates and Equation (1) to compute probabilities of victory given different incumbency histories. For comparison, the horizontal axis features the same measure of PRI entrenchment as in Figure 5 -i.e., the share of the past $N=5$ electoral cycles won by PRI. We then take the empirical 
distribution of incumbency histories consistent with each possible level of PRI entrenchment, and we plot means (solid lines) and 95\% confidence intervals (dashed) of parties' probabilities of victory. As shown, entrenchment has a sizable impact on PRI's electoral success at the expense of opposition parties, more than doubling its probability of winning from $27 \%$ with no previous victories to $65 \%$ with no defeats.
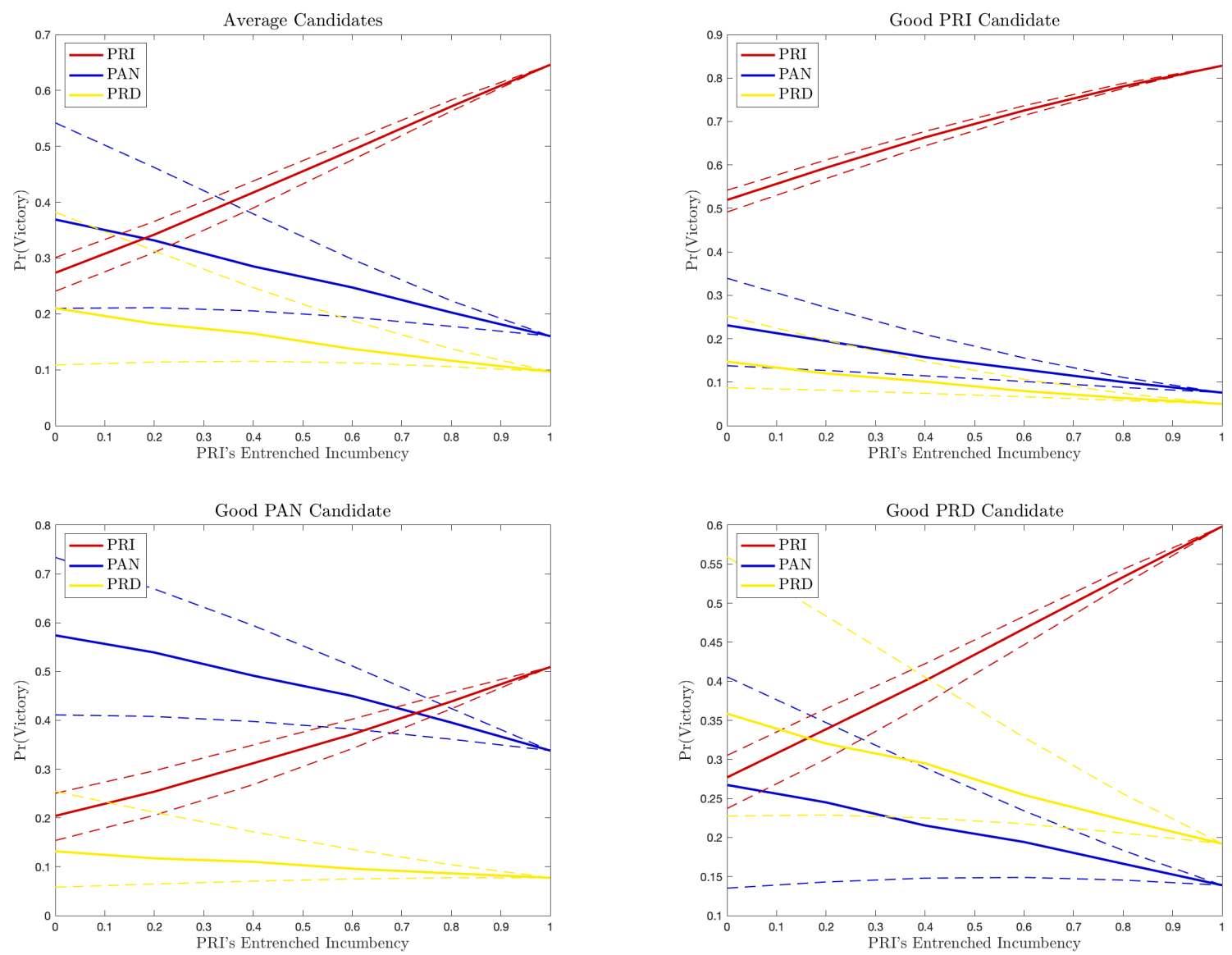

Figure 6: Entrenched Incumbency, Unobserved Valence, and Electoral Prospects

Notes. This figure shows, for a representative municipality, the predicted probability of victory by each major party (PRI, PAN, PRD) as a function of PRI's entrenchment under different unobserved valence scenarios. Predictions are computed using Equation (1) and corresponding coefficient estimates. Solid lines depict means, and dashed lines delimit 95\% confidence intervals, taking into account the empirical distribution of incumbency histories. In the top-left panel, we set unobserved valence to zero $\left(\xi^{p}=0\right)$-i.e., an "average" candidate - for all parties. In the remaining panels, predicted probabilities are computed conditional on a "good" candidate $\left(\xi^{p}=1\right)$ from PRI (top-right), PAN (bottom-left), and PRD (bottom-right).

While these results echo the reduced-form evidence in Figure 5, they explicitly control for the influence of unobserved features of the electoral environment (e.g., competence, charisma, 
campaign efforts). We quantify this influence in the remaining panels of Figure 6. Using our estimate $\hat{\pi}$ of the distribution of unobserved valence across candidates, we recompute parties' probabilities of victory as a function of PRI entrenchment under three scenarios: for PRI (top-right), PAN (bottom-left), and PRD (bottom-right), we condition on the event that the corresponding party draws a high-valence or "good" candidate $\left(\xi^{p}=1\right){ }^{27}$ The consequences are considerable. On average, parties' electoral prospects improve by about 20 percentage points following a good valence draw (and similar effects in the opposite direction result from "bad" candidate draws).

Taken together, these findings help elucidate the rationale behind the PAN-PRD alliance. As is clear from Figure 6, when PRI entrenchment is high, PAN and PRD face a highly disadvantageous environment wherein, unless candidate valence draws are favorable (and, for PRD, perhaps not even then), their prospects for victory running independently are extremely limited. However, pooling resources in support of a common candidate may provide a valence boost that the parties can exploit to level the playing field in the future (?). Indeed, our estimate of candidates' valence distribution, $\hat{\pi}$, confirms this: while PAN and PRD have on average only a $26 \%$ and $20 \%$ chance, respectively, of drawing a good candidate when running independently, the probability roughly doubles to $45 \%$ for a PAN joint candidate and $43 \%$ for a PRD joint candidate. This opens the door to defeating PRI, depleting its entrenched incumbency, and thus making future elections more competitive.

To show this logic at work, we compare in the top panels of Figure 7 the estimated posterior probability of drawing a high-valence candidate when running in coalition versus independently. ${ }^{28}$ In the top-left panel of the figure, we compute, for each election in our data, the (counterfactual) difference in the estimated posterior probability of a high-valence coalition versus independent candidate from PAN. We separately plot the distribution of this difference across races where PAN and PRD jointly nominate a PAN candidate (solid) and those where

\footnotetext{
${ }^{27}$ For instance, when $\xi^{\text {PRI }}=1$, we use $\hat{\pi}$ to integrate over the conditional distribution of the remaining parties' candidates' valence.

${ }^{28}$ Application of the EM algorithm in our estimation procedure yields these posteriors (see Appendix D), which can be taken as probabilistic estimates of realized valence draws in the municipal races in our sample.
} 
they run independently (dashed). The top-right panel shows analogous distributions for PRD candidates.
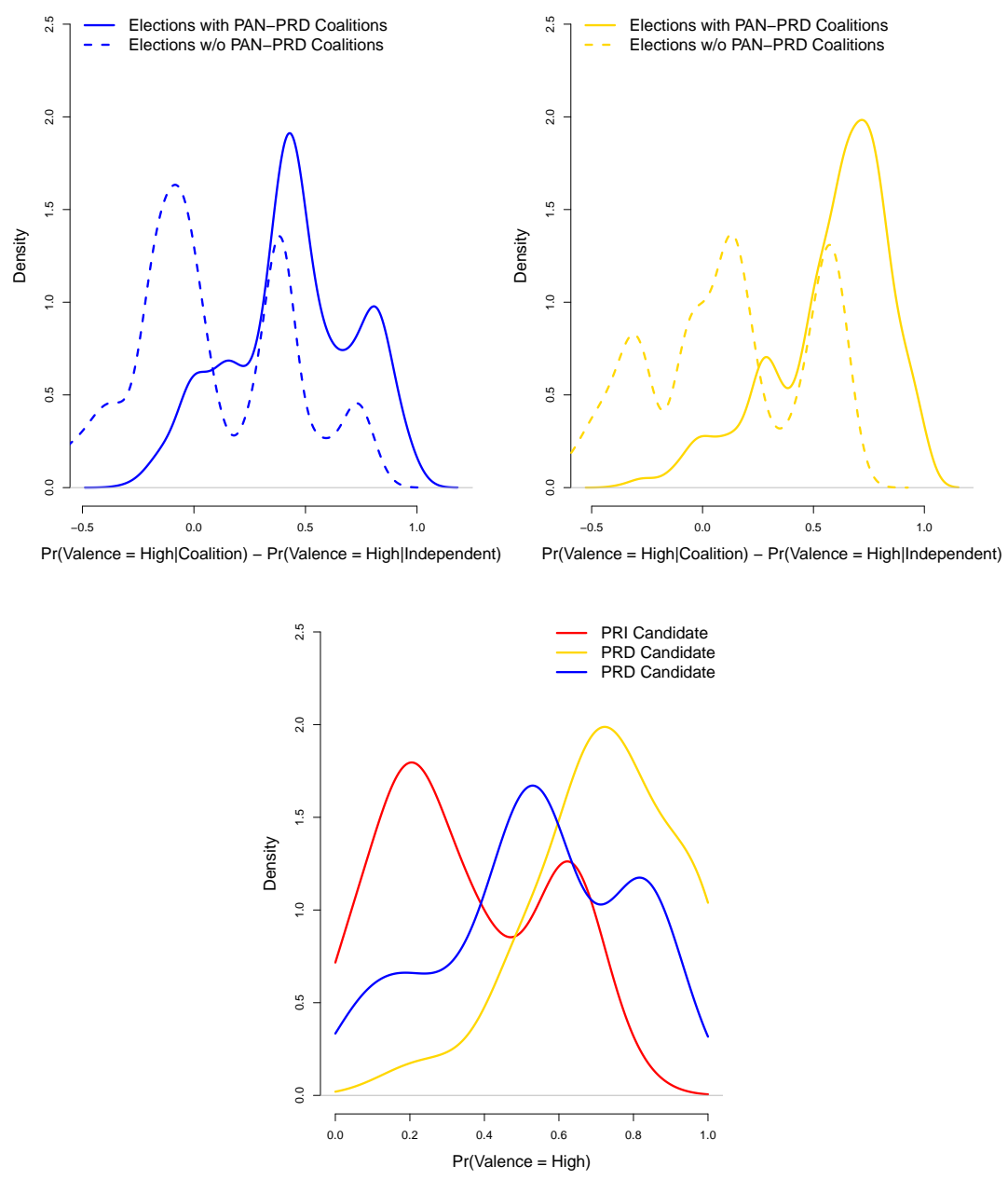

Figure 7: Posterior Probabilities of High-Valence Candidates

Notes. The top-left panel of this figure shows the distribution - across municipal races with (solid) and without (dashed) PAN-PRD coalition candidates - of the difference in the estimated posterior probability of drawing a high-valence PAN candidate when running in coalition with PRD versus independently. The top-right panel shows analogous distributions for PRD candidates. The bottom panel shows the distribution - across municipal races with coalition candidates - of the estimated posterior probability of drawing a high-valence candidate from PRI (red), PAN (blue), or PRD (yellow) conditional on a joint PAN-PRD nomination.

In races where PAN and PRD choose to join forces, it is clear from Figure 7 that the valence gap between coalition and independent candidates is a crucial consideration. Recall that our estimate $\hat{\pi}$ of the ex-ante distribution of valence uncovers a considerable advantage for coalition candidates: as noted above, the average ex-ante gaps in the probability of a high- 
valence draw are 19 and 23 percentage points, respectively, for PAN and PRD candidates. Yet the corresponding average posterior gaps (solid) in the top panels of Figure 7 are 44 and 58 percentage points for PAN and PRD, respectively. This implies that the parties rely heavily on superior valence when they choose to join forces, which underscores the importance of appropriately accounting for this selection process in our empirical analysis. Moreover, as shown in the bottom panel of Figure 7, selection on valence pays off. For PRI (red), PAN (blue), and PRD (yellow), we plot the distribution of the estimated posterior probability of a high-valence candidate across races with coalition candidates. Notice that PAN-PRD candidates considerably outperform PRI candidates in this respect. While PAN and PRD coalition candidates have average posterior probabilities of being high-valence of $54 \%$ and $72 \%$, respectively, the average posterior probability for PRI candidates is only $35 \%{ }^{29}$

\subsection{Parties' Payoffs}

Our estimates of $\beta$ and $\pi$ reveal that the PAN-PRD coalitions are consistent with a long-term coping strategy by parties competing in a dynamically disadvantageous environment. It is still possible, however, that the coalition partners may not face much of a short-run tradeoff if ideology is not a salient consideration. We present in Figure 8 our estimates of parties' payoffs, $\hat{\theta}_{p p^{\prime}}$, along with $95 \%$ confidence intervals. ${ }^{30}$ As in the case of ideal-point estimation in item-response models, in addition to the normalization $\theta_{p p}=0$ discussed in Section 4.2 , we impose an anchoring restriction on $\theta: \theta_{\mathrm{PAN}, \mathrm{PRI}}=\theta_{\mathrm{PRD}, \mathrm{PRI}}$. This facilitates comparisons of parties' payoffs on a common scale.

In line with parties' national ideological positions and the RDD evidence in Section 3.1, we find that, at the municipal level, both PAN and PRD suffer a larger payoff loss when the other is in power than when the centrist PRI wins an election. While PAN appears to have a weaker preference for PRI over PRD than PRD does for PRI over PAN, we cannot disentangle,

\footnotetext{
${ }^{29}$ In fact, the distributions for PAN and PRD candidates both first-order stochastically dominate PRI's.

${ }^{30}$ Figure B3 in Appendix B shows our estimates of PAN's bargaining power $\left(\lambda_{s}\right)$ relative to PRD across states.
} 


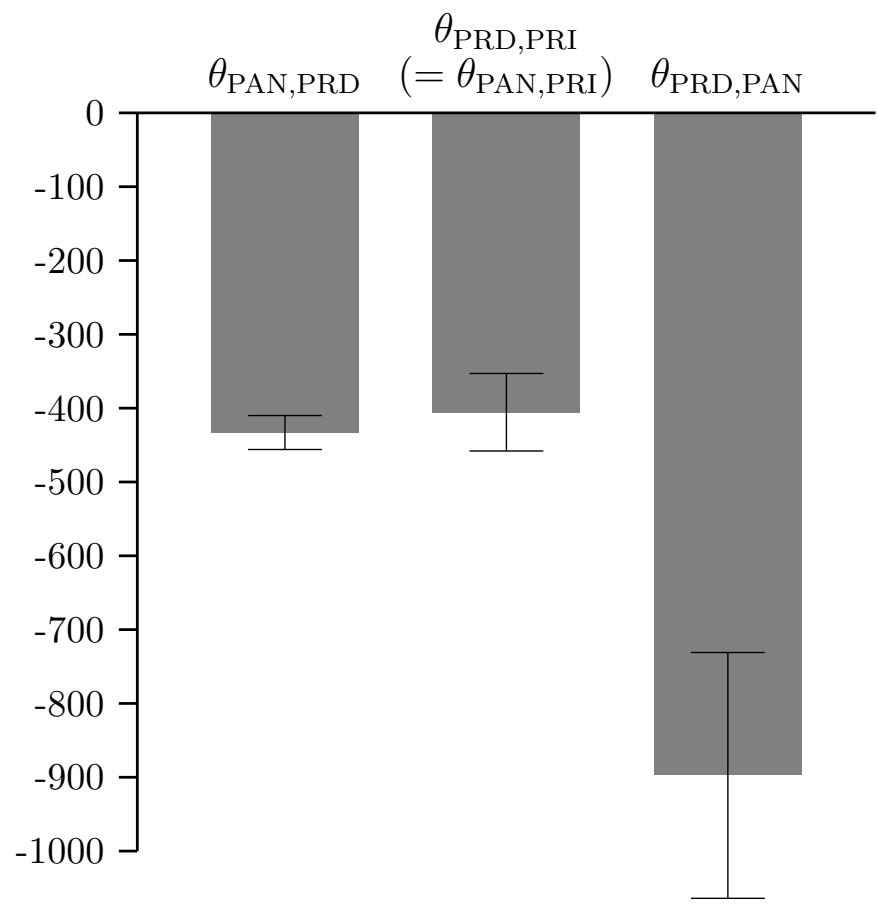

Figure 8: Parties' Payoffs

Notes. This figure presents our estimates of $\theta_{\mathrm{PAN}, \mathrm{PRD}}, \theta_{\mathrm{PRD}, \mathrm{PRI}}$, and $\theta_{\mathrm{PRD}, \mathrm{PAN}}$, where $\theta_{p p^{\prime}}$ denotes the payoff party $p$ derives whenever party $p^{\prime}$ is in power. Recall that $\theta_{p p}=0$ and $\theta_{\mathrm{PAN}, \mathrm{PRI}}=\theta_{\mathrm{PRD}, \mathrm{PRI}}$.

as noted in Section 4.2, whether this is due to ideological proximity or to heterogeneity in the value of office for each party. Indeed, the RDD evidence in Figure 3 suggests that PRI is closer ideologically to PAN than to PRD. Nevertheless, given our results in the previous section, it is clear that, by supporting their partner's candidate, PAN and PRD not only forego their favorite outcome - winning the election - but they substantially raise the probability of their least preferred outcome - their partner winning the election. This short-term loss is only justified by the benefits, outlined above, the coalition reaps if successful: depleting PRI's entrenched incumbency and thus leveling the future playing field.

\subsection{Counterfactual: No Coalitions}

Having uncovered the rationale behind the PAN-PRD alliance, we turn to quantifying its impact. With our estimated structural parameters in hand, we simulate municipal election outcomes in Mexico under a counterfactual scenario wherein we prevent PAN and PRD from 
ever joining forces. That is, for each municipality in our data that experiences at least one PAN-PRD coalition, we use our estimates of parties' electoral prospects given independent PAN and PRD candidates, $f_{0 m t}^{p}(\cdot ; \hat{\beta})$, to simulate election outcomes from the first such occurrence onward.

Figure 9 presents our results. For municipalities with PAN-PRD coalitions, the bar plot shows in gray the actual share of municipal election victories by each party as observed in the data, and in white it shows the corresponding average counterfactual shares along with $95 \%$ confidence intervals across 10,000 simulations. ${ }^{31}$
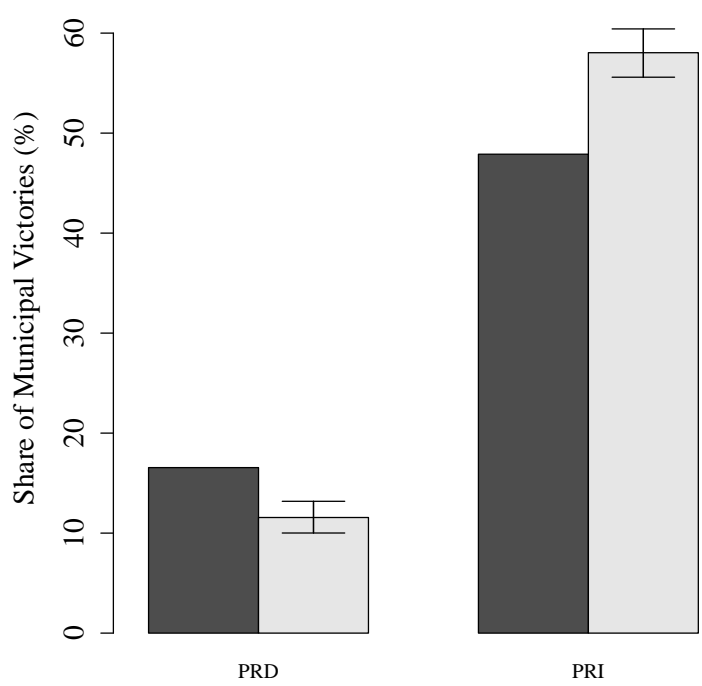

- Observed

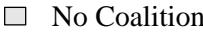

Figure 9: Election Outcomes with and without PAN-PRD Coalitions

Notes. For municipalities that experience at least one PAN-PRD coalition, this figure shows in gray the actual share of municipal election victories by each major party (PRI, PAN, PRD). In white, the figure shows the corresponding expected victory shares - along with 95\% confidence intervals across 10,000 simulations - under a counterfactual scenario with no PAN-PRD coalitions.

As expected, we find that, had PAN and PRD never joined forces, PRI's dominance in Mexican local politics would have been even greater. The magnitude is considerable: while PRI's share of victories is $48 \%$ in the data, it could have been almost $60 \%$ without the PAN-PRD alliance. Interestingly, the coalition's gains are fairly evenly split between the two partners: PAN and PRD each enjoy about a 5 percentage point increase in their

\footnotetext{
${ }^{31}$ Figure B4 in Appendix B shows PRI's corresponding shares over time.
} 
share of victories. This has substantial implications for democratic consolidation in Mexico following decades of one-party rule by PRI. In particular, among municipalities with PANPRD coalitions, 26 have never experienced a transfer of power. This number could have been $50 \%$ higher without the PAN-PRD alliance, with a 95\% confidence interval between 31 and 48 municipalities.

\subsection{Case Study: Jalisco}

We conclude our analysis, after taking a broad look at the consequences of the PAN-PRD alliance, by zeroing in on a particular state: Jalisco. Our sample covers two electoral cycles. In 2012, PAN and PRD ran independently in every municipality. In 2015, however, PAN and PRD joined forces in 33 out of 124 municipalities: 25 with a PAN coalition candidate and 8 with a PRD candidate - see Figure B1 in Appendix B. Notably, we estimate $\hat{\lambda}_{\mathrm{JAL}} \approx 1$, consistent with the state being a historical PAN stronghold relative to PRD, which makes Jalisco a particularly interesting case study for our model. First, our model must capture the remarkable variation in PAN-PRD coalition choices in the state, both over time and across municipalities. Moreover, it should explain why, in a state where we estimate PAN essentially has full discretion over coalition choices, would the party agree to stand down in 8 municipalities to support PRD candidates.

Our model correctly predicts over $95 \%$ of observed coalition choices - in particular, 24/25 and 7/8 municipalities with PAN and PRD coalition candidates in 2015, respectively. Consistent with standard discrete-choice intuition, such predictions follow from correctly estimating that the conditional value, $v_{j m t}\left(z_{m t} ; \hat{\varphi}\right)$, associated with the choice observed in the data is greater than that of any alternative. Unlike static discrete choice, however, these conditional value functions are defined implicitly by costly fixed-point calculations-Equation (4) — that encode the long-term impact of each alternative. Next, to better understand the choices observed in the data, we unpack the coalition's dynamic considerations, focusing on the most 
immediate consequences of alternative coalition configurations. ${ }^{32}$

First, we note that, in the 5 electoral cycles prior to 2012, PRI and PAN won $46 \%$ and $43 \%$, respectively, of mayoral races in Jalisco. This illustrates PAN's relative competitiveness in the state and underlies the party's decision to run independently in 2012. However, PRI won almost $70 \%$ of Jalisco's municipalities that year. As predicted by our model, PRI's resounding success altered PAN's dynamic calculus, compelling the party to join forces with PRD in over a quarter of municipalities in 2015.

Table 1 presents parties' estimated net accumulated incumbency, $\iota\left(I_{m t}^{p}, \hat{\alpha}\right)$, in 2012 and 2015. We report averages over municipalities according to PAN and PRD's coalition choice in 2015. Three takeaways emerge. First, while PRI's accumulated incumbency rose from 2012 to 2015 throughout Jalisco, it rose the least and was lowest in 2015 among municipalities where PAN ran independently. In addition, according to PAN's net incumbency, PAN was most competitive in these municipalities, mitigating incentives to nominate coalition candidates. The top panel of Figure 10 shows a scatterplot of the counterfactual predicted probability of victory of a PAN coalition candidate versus that of each observed independent PAN candidate. Consistent with PAN's choice, independent candidates were indeed more competitive, eliminating the need to join forces with PRD.

Second, PRI's accumulated incumbency was lowest in 2012 but rose the most among municipalities with PAN coalition candidates. This suggests these municipalities were the easiest targets for the PAN-PRD alliance to regain ground from PRI. Moreover, PAN was more competitive than PRD in these municipalities according to their accumulated incumbencies. Unsurprisingly, then, PAN headlined the PAN-PRD coalition in these 2015 races. The bottomleft panel of Figure 10, analogous to the top panel, reveals that observed PAN coalition candidates were in fact considerably more competitive than counterfactual independent PAN candidates, justifying PAN's choice.

Third, PRI's incumbency was already highest in 2012 and nevertheless rose substantially

\footnotetext{
${ }^{32}$ This is another key advantage of the structural enterprise: while a reduced-form analysis of PAN-PRD coalition choices may also attain high predictive success, our approach allows us to disentangle the fundamental forces underlying our model's predictions.
} 
Table 1: Parties' Net Incumbency in Jalisco by 2015 PAN-PRD Coalition Choice

\begin{tabular}{lccc}
\hline \hline & $\begin{array}{c}\text { Independent } \\
\text { Candidates (2015) }\end{array}$ & $\begin{array}{c}\text { PAN Coalition } \\
\text { Candidate (2015) }\end{array}$ & $\begin{array}{c}\text { PRD Coalition } \\
\text { Candidate (2015) }\end{array}$ \\
\hline PRI's Net Incumbency (2012) & 2.157 & 2.010 & 2.338 \\
PRI's Net Incumbency (2015) & 2.255 & 2.298 & 2.463 \\
PRD's Net Incumbency (2012) & 0.144 & 0.637 & 1.177 \\
PRD's Net Incumbency (2015) & 0.135 & 0.480 & 1.070 \\
PAN's Net Incumbency (2012) & 2.200 & 1.702 & 1.176 \\
PAN's Net Incumbency (2015) & 2.038 & 1.536 & 1.032 \\
\hline \hline
\end{tabular}

Notes. This table reports parties' estimated net accumulated incumbency, $\iota\left(I_{m t}^{p}, \hat{\alpha}\right)$, in 2012 and 2015 . The first column averages over municipalities where PAN and PRD ran independent candidates in 2015 . The second and third columns average over municipalities with PAN and PRD coalition candidates, respectively.

in 2015 among municipalities with PRD coalition candidates. As a result, these were the toughest races, where PAN was least competitive. Furthermore, these municipalities were the most favorable to PRD, with PRD's accumulated incumbency surpassing PAN's in 2015. As shown in the bottom-right panel of Figure 10, PRD coalition candidates were more competitive on average than counterfactual PAN coalition candidates, who in turn were more competitive than counterfactual independent PAN candidates. This alone, however, doesn't explain PAN's choice to stand down in support of PRD candidates. As discussed, from a short-term perspective, PAN would prefer PRI to win over PRD. Yet Figure 11 illustrates the dynamic benefit for PAN from supporting PRD candidates. Looking ahead at the 2018 electoral cycle, our model indicates that independent PAN candidates would be considerably more competitive in these municipalities following a PRD coalition victory in 2015 than under a further entrenched PRI incumbent.

Overall, this exercise highlights the remarkable heterogeneity in incentives for and consequences of coalition choices that our model, while parsimonious, is able to capture. And it corroborates the dynamic logic behind the PAN-PRD alliance. 

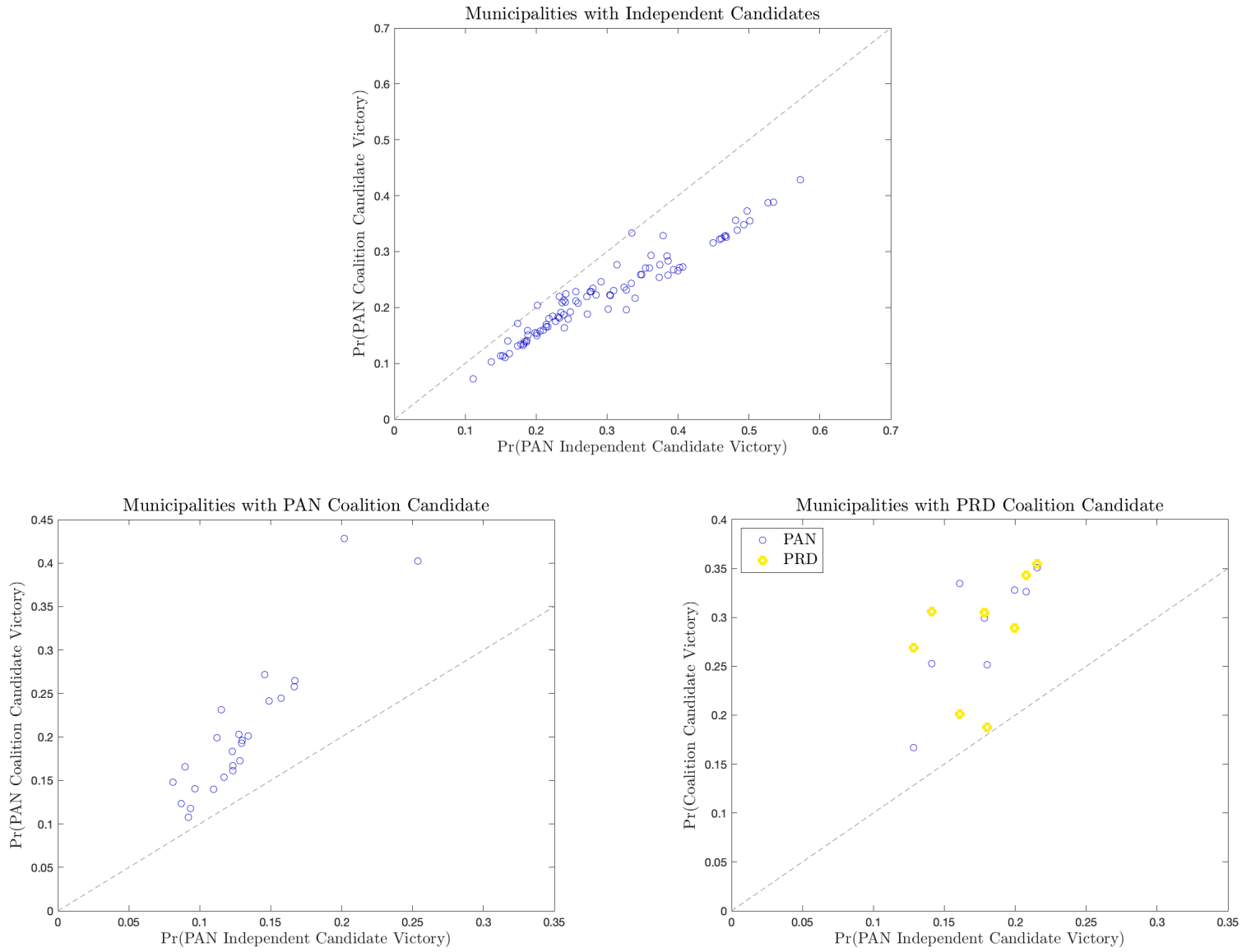

Figure 10: Counterfactual Electoral Performance, Jalisco 2015

Notes. This figure shows scatterplots of the probability of victory in 2015 by a PAN (blue) or PRD (yellow) coalition candidate (vertical axis) against that of an independent PAN candidate (horizontal axis). Predictions are computed using Equation (1) and corresponding coefficient estimates. The $45^{\circ}$ line (dashed) is shown in gray. We provide separate plots for municipalities where, in 2015, PAN and PRD nominated independent candidates (top), a PAN coalition candidate (bottom-left), or a PRD coalition candidate (bottom-right). 


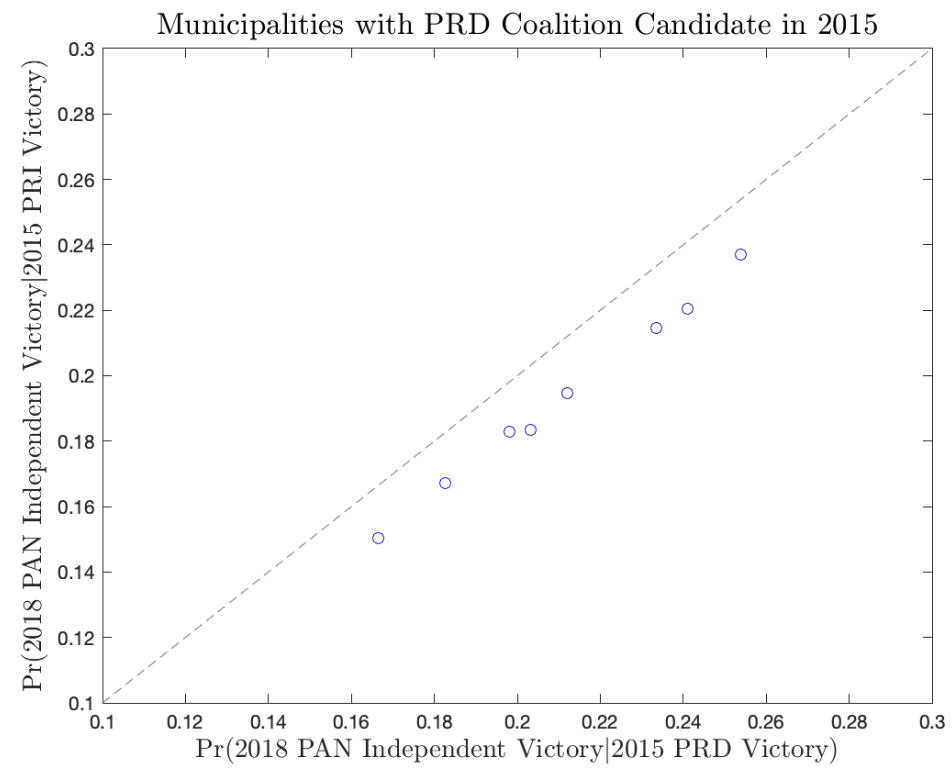

Figure 11: 2018 PAN Electoral Performance Conditional on 2015 Outcome

Notes. The horizontal axis of this scatterplot measures the probability of victory by an independent PAN candidate in 2018 conditional on a PRD coalition candidate victory in 2015. The vertical axis measures the corresponding probability conditional on a PRI victory. The $45^{\circ}$ line (dashed) is shown in gray. 